\title{
DIREITO E SUSTENTABILIDADE: OS ACIDENTES ECOLÓGICOS E AS PERÍCIAS AMBIENTAIS
}

\author{
LAW AND SUSTAINABILITY: \\ ECOLOGICAL ACCIDENTS AND ENVIRONMENTAL SKILLS
}

${ }^{1}$ Adriano Fábio Cordeiro da Silva

\section{RESUMO}

Este trabalho aborda os esforços e reações mundiais frente aos acidentes ecológicos e o surgimento do Direito Ambiental. A metodologia desenvolvida foi a da pesquisa bibliográfica, envolvendo os diversos meios de informação. Tem por objetivo descrever os vestígios históricos e crescente complexidade das atividades periciais. Aborda as discussões sobre o conceito de Direito e o Meio Ambiente ecologicamente equilibrado como espécie dos direitos humanos, pondera sobre as influências do capitalismo, o dinamismo incontornável das forças da natureza, e os sistemas legais que reconhecem a natureza como sujeito de Direitos. Apresenta a sustentabilidade como um desafio e imperativo ético da humanidade.

Palavras-chave: Acidentes Ecológicos; Perícias Ambientais; Sujeitos de Direito; Capitalismo; Natureza; Sustentabilidade.

\begin{abstract}
This paper addresses the global efforts and reactions related to ecological accidents and the emergence of environmental law. The used methodology was literature research, involving variety of media. This paper aims to describe the historical remains and increasing complexity of expert activities. It addresses the discussions on the concept of law and ecologically balanced environment as part of human rights, and raises questions on the influences of capitalism, undeniable dynamism of the nature forces, and legal systems that recognize the nature as a subject of rights. It presents sustainability as a challenge and ethical imperative of humankind.
\end{abstract}

Keywords: Ecological Accidents; Environmental Skills; Law Subjects; Capitalism; Nature. Sustainability;

\footnotetext{
${ }^{1}$ Doutorando em Direito Econômico e Social pela Pontifícia Universidade Católica do Paraná - PUCPR, Paraná (Brasil). Professor efetivo Universidade de Pernambuco - UPE, Pernambuco (Brasil).

E-mail: adrianofabio@hotmail.com
} 


\section{INTRODUÇÃO}

A humanidade está diante de um desafio ético que se iniciou há muito tempo. Desde a Revolução Industrial que o modo de vida da população foi impactado pelos novos mecanismos de produção em massa, que indiscutivelmente trazem conforto, mas alguns deles são demasiado danosos ao meio ambiente.

Dissociar os conceitos de crescimento econômico e desenvolvimento é tarefa primária para o entendimento da complexidade dos dias atuais. Nada justifica as ideias do passado onde o crescimento a qualquer preço se sobrepunha ao desafio de se promover um modelo de desenvolvimento sustentável de forma igualitária, acessível e menos impactante ao meio ambiente.

Quais as repercussões dos principais acidentes ecológicos mundiais e os vestígios históricos das atividades periciais dos nossos tempos? Qual a evolução do conceito do Direito e do meio ambiente ecologicamente equilibrado como espécie dos Direitos Humanos? Existe a possibilidade jurídica de se reconhecer a natureza enquanto sujeito de direitos? Como se da o entrelaçamento das forças que constituem a dinâmica do capitalismo, da natureza e do Direito?

Buscando respostas para estes instigantes temas, sem a pretensão de esgotá-las, realizou-se uma pesquisa bibliográfica, através dos mais diversos meios de comunicação e de analises doutrinárias sobre a discussão evolutiva desses conceitos.

A temática abordada nesta pesquisa é atual e relevante, uma vez que a humanidade enfrenta os desafios da sustentabilidade, ao tempo em que os sistemas jurídicos já reconhecem o Direito ao meio ambiente ecologicamente equilibrado como Direito Humano, portanto, mantem-se o interesse precípuo de analisar objetiva e sumariamente estes pontos estratégicos para a compreensão da abrangência dos Direito, da influência do sistema econômico e aperfeiçoamento das técnicas periciais sob a perspectiva da melhoria dos atuais padrões de sustentabilidade, enquanto imperativo ético.

\section{DOS ACIDENTES ECOLÓgICOS E INICIATIVAS MUNDIAIS VOLTADAS A DISCUSSÃO JURÍDICA E SOCIAL DOS SEUS EFEITOS}

Diversos acidentes provaram a humanidade que os custos ambientais foram e são 
severos e desproporcionais, quando comparados aos benefícios sociais e econômicos que as velhas formas de crescimento implementaram, dos quais são exemplos, os efeitos danosos identificados como resultantes do despejo de efluentes industriais na Baía de Minamata, no Japão; pelos acidentes Flixborough, na Inglaterra; pela emissão do agente laranja em Seveso Chemical, na Itália; pelo acidente nuclear de Three Mile Island, Harrisburg, Pensilvânia nos EUA; explosão de navio petroleiro nos mares de Cape Town, África do Sul; vazamento de isocianato de metila em Bhopal, na Índia; o desastre nuclear de Chernobyl, na Ucrânia (quando integrante da extinta União Soviética); incluindo-se, também, os derramamentos de petróleo marítimo com petroleiros (Atlantic Express, Amoco Cadiz, Torrey Canyon e Exxon Valdez); e o acidente com material radiológico em Goiânia no Brasil.

Para melhor visualizar a historicidade dos primeiros acidentes ecológicos em escala global e o encadeamento das ocorrências dos acidentes pelos diversos continentes, observa-se o quadro abaixo onde se especificam o ano, continente, local, acidente e os principais impactos sociais suportados pela população das regiões diretamente afetadas.

QUADRO 1 - Primeiros Acidentes Ecológicos e Impactos Sociais

\begin{tabular}{|c|c|c|c|c|}
\hline Ano & Continente & Local & Acidente & Impactos sociais \\
\hline 1956 & Ásia & $\begin{array}{l}\text { Japão } \\
\text { Baía de } \\
\text { Minamata }\end{array}$ & $\begin{array}{l}\text { Despejo de efluentes industriais na Baía de } \\
\text { Minamata. }\end{array}$ & $\begin{array}{l}12,5 \text { mil pessoas foram contaminadas por } \\
\text { ingestão de peixes impregnados por } \\
\text { mercúrio. }\end{array}$ \\
\hline 1974 & Europa & $\begin{array}{l}\text { Inglaterra } \\
\text { Flixborough }\end{array}$ & $\begin{array}{l}\text { Explosão na planta de produção de } \\
\text { caprolactama na fábrica Nypro Factory } \\
\text { Ltda. }\end{array}$ & $\begin{array}{l}\text { Pouco mais de } 1,8 \text { mil habitações e cerca } \\
\text { de } 167 \text { estabelecimentos comerciais num } \\
\text { raio de } 13 \text { quilômetros do local foram } \\
\text { danificados. }\end{array}$ \\
\hline 1976 & Europa & $\begin{array}{l}\text { Itália } \\
\text { Seveso }\end{array}$ & Emissão do agente laranja & $\begin{array}{l}\text { Nuvem ultratóxica matou } 50 \text { mil animais } \\
\text { e fez o Vaticano autorizar mais de dois } \\
\text { mil abortos. }\end{array}$ \\
\hline 1979 & $\begin{array}{l}\text { América } \\
\text { do Norte }\end{array}$ & $\begin{array}{c}\text { EUA } \\
\text { Pensilvânia }\end{array}$ & $\begin{array}{l}\text { Derretimento nuclear da unidade dois da } \\
\text { central da usina de Three Mile Island. }\end{array}$ & $\begin{array}{l}200 \text { mil pessoas abandonaram } \\
\text { forçosamente a região. }\end{array}$ \\
\hline 1983 & África & $\begin{array}{c}\text { África } \\
\text { do Sul } \\
\text { Cape Town }\end{array}$ & $\begin{array}{l}\text { Depois de um incêndio a bordo, seguido de } \\
\text { explosão, o navio espanhol Castillo de } \\
\text { Bellver rachou-se ao meio, liberando cerca } \\
\text { de } 200 \text { milhões de litros do óleo na costa de } \\
\text { Cape Town. }\end{array}$ & $\begin{array}{l}\text { Afetou a biodiversidade marinha e a } \\
\text { atividade pesqueira da região. }\end{array}$ \\
\hline 1984 & Ásia & $\begin{array}{l}\text { Índia } \\
\text { Bhopal }\end{array}$ & $\begin{array}{l}\text { Vazamento em um tanque de } \\
\text { armazenamento subterrâneo de isocianato } \\
\text { de metila. }\end{array}$ & $\begin{array}{l}\text { Matou imediatamente } 8 \text { mil pessoas e } \\
\text { outras } 16 \text { mil a posteriori, cuja } \\
\text { contaminação atingiu um total de mais de } \\
500 \text { mil habitantes. }\end{array}$ \\
\hline 1986 & Europa & $\begin{array}{l}\text { Ucrânia } \\
\text { Chernobyl }\end{array}$ & $\begin{array}{l}\text { Pior acidente da história com usina nuclear, } \\
\text { cujo número de vítimas continua sendo um } \\
\text { mistério. }\end{array}$ & $\begin{array}{l}\text { Matou mais de } 10 \text { mil pessoas na Ucrânia } \\
\text { (quando integrante da extinta União } \\
\text { Soviética). }\end{array}$ \\
\hline 1987 & $\begin{array}{l}\text { América } \\
\text { do Sul }\end{array}$ & $\begin{array}{l}\text { Brasil } \\
\text { Goiânia }\end{array}$ & $\begin{array}{l}\text { Aparelho contendo peça radioativa que } \\
\text { projetava uma luz brilhante foi abandonado } \\
\text { e manuseado por diversas pessoas. }\end{array}$ & $\begin{array}{l}\text { Mais de mil pessoas foram contaminadas } \\
\text { por radiação de Césio-137 em Goiânia. }\end{array}$ \\
\hline
\end{tabular}

Fonte: Elaborado pelo autor. 
Estes e outros desastres ambientais e suas repercussões sócio-econômico-ambientais provocaram e continuam a desafiar a humanidade quanto a uma permanente e complexa atividade de investigação e mudança político-técnica e jurídico-científica de cuja imprescindibilidade, não se pode mais nem protelar ou abster-se.

Contudo, somente depois que estes fatos graves ocorreram, todos causados por
intervenção humana na busca de um desenvolvimento industrial desmedido, e que
vozes de peso soaram alertando que esses ataques ao meio ambiente pudessem
produzir efeitos para toda a humanidade, é que se começou a tomar consciência da
necessidade de se criarem organismos políticos e estruturas jurídicas para protegê-lo.
Foi a partir daí que surgiu a preocupação com a implementação de normas jurídicas
específicas, portanto, de um direito próprio com o claro intuito de proteger o meio
ambiente. (BARROS, 2008, p. 3)

A ação humana provocou diversos acidentes ecológicos trazendo esta preocupação para um novo ramo da ciência jurídica, o Direito Ambiental, desafiando a humanidade ao enfrentamento das questões ambientais e suas implicações geopolíticas, fazendo surgir diversos estudos técnicos, conclaves, iniciativas, convenções mundiais e organismos internacionais voltados para discussão da sustentabilidade, fazendo aflorar as discussões de políticas para adoção de medidas mitigadoras dos efeitos danosos dos modelos de crescimento econômico até então adotados.

\subsection{Iniciativas Mundiais}

Em decorrência destes e doutros crescentes problemas ecológicos que se iniciaram intensamente no século passado, em 1970, cientistas de vários países, especialmente da Europa, reuniram-se na Itália e instituíram o Clube de Roma, visando discutir a questão ambiental de forma mundial e em escala planetária.

Como resultados técnicos e factíveis destas reuniões político-científicas, muitos relatórios foram elaborados e divulgados, dentre eles o mais polêmico intitulado "Os Limites do Crescimento", datado de 1972, onde se defendia que o desenvolvimento econômico no Terceiro Mundo deveria ser zerado, para se evitar maiores degradações ambientais no Planeta.

Apareceram e evoluíram com abrangência mundial os movimentos sociais, as Organizações Não Governamentais - ONGS, as ações e esforços convencionais dos governos, sociedade e comunidades científicas, voltados à discussão e a busca de soluções para o conflito ecológico e proteção ao meio ambiente. Destes são exemplos, as Conferências Mundiais do Meio Ambiente e Desenvolvimento e suas respectivas Declarações em 
Estocolmo e Rio de Janeiro; o Protocolo de Kyoto; o Programa das Nações Unidas para o Meio Ambiente - PNUMA; a Rede WWF, anteriormente conhecida como Fundo Mundial para a Natureza; a União Internacional para a Conservação da Natureza - IUC. No Documentário Uma Verdade Inconveniente, produzido pelo ex-vice-presidente dos EUA, Al Gore; além de diversas legislações e políticas públicas regulamentadas pelos Estados.

Paulatina e paralelamente a todos estes movimentos e esforços, iniciou-se, também, as ações radicais do navio Rainbow Warrior, da organização Greenpeace que visavam denunciar, escandalosamente, ao mundo, os malefícios do progresso e dos danos ecológicos e ambientais provocados pelo homem, governo e corporações. Estes são, sumariamente, exemplos mundiais, do início e desenvolvimento dos movimentos ecológicos de opinião.

\footnotetext{
Os movimentos ecológicos de opinião surgiram por volta dos anos sessenta, rapidamente se desenvolveram e se disseminaram em todo o globo terrestre. A sociedade percebeu a importância de preservar o meio ambiente, sendo cada vez mais crescente o uso de práticas ecologicamente corretas, com o objetivo de se estabelecerem condutas socialmente desejáveis. Gradualmente, consolida-se a ideia de que o solo cultivável, os minerais, a qualidade do ar, da água e dos alimentos estão comprometidos, e os recursos naturais mais esgotáveis. (TOCCHETO, 2010, p. 3).
}

As novas dinâmicas sociais são complexas e exigem novas formas e meios científicos para se quantificar os danos advindos do processo civilizatório. Assim, os modelos e concepções de crescimento e desenvolvimento econômicos nunca estiveram sob tanta pressão para que se atualizem numa velocidade cada vez maior de modo a identificar, quantificar e reparar os mais diversos danos, por meio da correta aplicação de técnicas e pelo entrelaçamento de múltiplas e diversas formas de atividades científicas, assunto sobre o qual se trata a seguir, apresentando inicialmente um sintético relato histórico sobre o surgimento e complexidade das atividades periciais.

\subsection{Vestígios Históricos das Periciais}

No passado e nas antigas civilizações as atitudes humanas eram exclusivamente subordinadas às leis divinas e os conflitos sobre o uso da terra, quando ocorriam, eram frequentemente dirimidos pela égide da força bruta.

Segundo Cabral (2010, p. 14), os vestígios históricos do surgimento de pericias datam do tempo da velha civilização egípcia, quando o rei Senusret (Sesóstris I) um dos faraós do Médio Império (2040 e 1640 a.c.), sorteou e concedeu lotes de terras aos seus 
súditos, limitando-as, divisando-as pelos acidentes topográficos naturais da região, entretanto, condicionou que os súditos lhe pagassem tributos pelo cultivo das terras, cujas divisas eram imprecisas e muito confusas.

Face as constantes polêmicas das divisas, ocorriam conflitos e desordens entre os súditos. Por exemplo, era comum que os limites geográficos de um rio, por inundações ou assoreamento, diminuísse, aumentasse ou até privasse do domínio do súdito áreas significativas ou até a integralidade de seu lote de terras, e isto alterava ou inviabilizava a condição de pagamento dos tributos cobrados pelo rei.

Quando estes incidentes ocorriam, os súditos procuravam o rei, relatavam o ocorrido e justificavam a incapacidade dos pagamentos dos tributos, o que era conferido posteriormente por inspetores ou encarregados do rei, que ficavam incumbidos de confirmar os relatos dos súditos, usando das técnicas primárias de geometria e agrimensura para a verificação da medição de terras ou atestando a veracidade dos fatos alegados, o que diminuía a obrigação do pagamento dos tributos na proporção da perda verificada. Estes são os vestígios históricos do surgimento das complexas e multidisciplinares atividades periciais dos nossos tempos.

$\mathrm{Na}$ Grécia antiga, aprofundam-se os conhecimentos dos egípcios, e já se encontram previsões em textos legais da atuação dos Peritos Agrimensores que já aquela época eram experts conhecedores das técnicas de geometria e medições.

Entre 550 a.C. - 486 a.C., o rei persa Dario I, dando seguimento a estrutura administrativa criada por Ciro o Grande, criou o sistema de fiscalização das províncias ou Satrápias. Historicamente, surgem as inspeções in loco com os inspetores-fiscais, chamados a época de olhos e ouvidos do rei, quando fiscalizavam, arbitravam e avaliavam as províncias, sendo estes inspetores-fiscais do passado, os antecessores dos peritos atuais, que hoje atuam nas demandas judiciais como os olhos e ouvidos técnicos do juiz.

$\mathrm{Na}$ idade média, inexistia o foro e quase não houve progresso das atividades periciais, face ao desprezo pela busca da verdade, pois prevalecia o fanatismo religioso e os conflitos e decisões eram resolvidas por duelos.

Somente a partir do século XI as perícias ressurgem com o Direito Romano e Canônico e com a influência da igreja, seguindo seu desenvolvimento especialmente após o século XIII com o desenvolvimento do comércio, quando ocorreu uma considerável disseminação e necessidade da perícia como instrumento de prova, especialmente na Grécia, 
França, Inglaterra e Itália.

Da crescente necessidade de aferição e de provas técnicas, evidencia-se o surgimento da busca constante da especialização pela sociedade industrial até os dias atuais, onde a perícia é vista como um conjunto de diligências realizadas por experts almejando elucidar, esclarecer, afastar ou dirimir dúvidas por meios de técnicas científicas ou empíricas, especialmente quando os fatos são objeto de complexos litígios judiciais ou extrajudiciais.

\subsection{Da Complexidade das Perícias Ambientais}

As demandas judiciais atualmente abrangem múltiplas questões e análises e são cada vez mais complexas, envolvem questões e repercussões jurídicas, dentre outras de natureza política, econômica, social, civil, criminal, administrativa e assim passaram a exigir uma miríade de especificidades e competências multidisciplinares de cuja atualização e desafios constantes, todos os que se dedicam a atividade pericial judicial ou arbitral, não podem jamais olvidar.

Sabe-se que os esforços demandados pela humanidade buscando proteger o meio ambiente não conseguiram nem conseguem dissociar os altos custos sociais e ambientais resultantes dos modelos de desenvolvimento até agora adotados, legitimados ou seguidos.

Surgem do impasse entre o direito ao meio ambiente ecologicamente equilibrado e o desenvolvimento de forma sustentável, diversos questionamentos técnicos sobre a quantificação, prevenção, precaução, indenização e reparação dos danos ambientais, impactos negativos e externalidades causadas pelos diversos fatores econômicos e sociais provenientes das atividades econômicas características, não só dos velhos tempos, mas também das novas e pós-modernas eras ou quadras temporais.

A amplitude protetiva e garantidora de direitos característicos de uma legislação ambiental desenvolvida para um mundo pós-moderno, tem contribuído para o reconhecimento e aceleração da litigiosidade e multiplicidade destas demandas, especialmente ao reconhecer às atuais e futuras gerações o direito humano de serem providos de condições ambientais adequadas à perpetuação de todas as espécies e diversidades de vida.

Daí a crescente dificuldade para se quantificar os danos e eficientemente valorá-los para as atividades econômicas indispensáveis a um compromisso legal de grandeza e 
complexidade intergeracional, especialmente quando adstritas a um julgo limitado por meios e formas processuais.

\begin{abstract}
A Perícia Ambiental Judicial é uma espécie de perícia judicial, determinada pelo juiz durante o trâmite de uma ação judicial, sendo um instrumento de prova que objetiva esclarecer fatos que exijam um conhecimento técnico específico para a sua exata compreensão, pois não se pode exigir do magistrado conhecimento pleno a respeito de todas as ciências humanas e exatas. Em todas as áreas técnico-científicas do setor humano, sobre as quais o conhecimento jurídico do magistrado não é suficiente para emitir opinião técnica a respeito, faz-se necessário uma perícia para apurar circunstâncias e/ou causas relativas a fatos reais, com vistas ao esclarecimento da verdade. De forma mais técnica a NBR (Norma Brasileira Regulamentar) 14653-1: 2011 define a perícia como: Atividade técnica realizada por profissional com qualificação específica, para averiguar e esclarecer fatos, verificar o estado de um bem, apurar as causas que motivaram determinado evento, avaliar bens, seus custos, frutos ou direitos. Nesse contexto, a Perícia Ambiental, como espécie de perícia, tem como objeto de estudo o meio ambiente, nos seus aspectos abióticos, bióticos e socioeconômicos, abrangendo a natureza e as atividades humanas (NUNES, 2014, p. 14)
\end{abstract}

Atualmente, a perícia ambiental está inserida num contexto de tensão entre o crescimento desmedido e a eficácia do princípio do desenvolvimento sustentável, servindo também de alicerce científico ao Direito Ambiental que se especializou na busca pela proteção ao meio ambiente.

O princípio do desenvolvimento sustentável procura conciliar a proteção do meio ambiente com o desenvolvimento sócio-econômico-ambiental para melhoria da qualidade de vida do homem. Visa à racionalização na utilização dos recursos naturais renováveis e não renováveis, com vistas a harmonizar a antiga ideia da existência de dicotomia entre "crescimento e meio ambiente", buscando realizar trade-offs eficientes. O conteúdo deste princípio é a manutenção das bases vitais da produção e reprodução do homem e de suas atividades, garantindo igualmente uma relação satisfatória entre os homens, e desses com o meio ambiente, para que as futuras gerações também tenham oportunidade de desfrutar dos mesmos recursos que temos hoje à nossa disposição. (FIORILLO, 2004, p. 58)

Sumariamente, a perícia ambiental tem como objetivo identificar, parametrizar, valorar, caracterizar os danos ambientais e suas consequências, promovendo o correto enquadramento legal das condutas e atividades lesivas e seus respectivos nexos de causalidade e imputação. Cabe frisar que objetivando acelerar a prestação jurisdicional, atualmente também são reconhecidas as formas de perícias ambientais arbitrais.

A perícia arbitral é realizada no juízo arbitral, instância criada pelas partes, cujo perito será o árbitro e enquanto árbitro é o juiz de fato, e sua atividade é arbitragem, e embora não seja judicialmente determinada, tem valor de perícia judicial, mas natureza extrajudicial, pois as regras serão determinadas pelas partes. Nesse sentido, denomina-se arbitragem a via de solução de conflito, alternativa ao sistema jurisdicional estatal, na qual um decisor é o árbitro, escolhido pelas partes, a quem se atribui a função de resolver o conflito segundo as regras, critérios e procedimentos por elas autorizados. Com efeito, [...] se comparada à prestação jurisdicional estatal, a arbitragem pode reduzir os custos de transação da prestação jurisdicional. Em 
primeiro lugar, em razão da agilidade com que é concluída. O procedimento arbitral não está sujeito à rigidez dos processos judiciais, não se submete ao regime dos infindáveis recursos a instâncias superiores, e os árbitros, não raro, contam com a infraestrutura necessária para que suas decisões sejam tomadas com grande rapidez. $\mathrm{Na}$ prestação jurisdicional estatal, o tempo de espera por uma decisão definitiva gera alto custo para as partes, que ficam privadas dos bens ou direitos litigiosos durante todos os anos que precedem o efetivo cumprimento da decisão transitada em julgado. Nesse caso, as partes arcam com o custo de oportunidade decorrente da privação dos bens e direitos disputados em Juízo. (NUNES, 2014, p. 20-21)

No Brasil, a perícia ambiental é especificamente regulada pelo Código de Processo Civil - Lei 13.105/2016, mas especificadamente em seus artigos 464 ao 484, que inclusive prevê a possibilidade da perícia consensual:

\begin{abstract}
O novo CPC inovou ao permitir que as partes, observadas as exigências feitas pelos incisos do caput do art. 471, escolham perito de comum acordo. Esta escolha - que o próprio novo CPC chama de 'perícia consensual' - substitui, para todos os fins, a prova pericial que seria realizada por perito nomeado pelo magistrado $\left(\S 3^{\circ}\right)$. Também cabe às partes, neste caso, indicar desde logo, concomitantemente à escolha do perito, seus assistentes técnicos, que acompanharão a perícia a ser realizada na data e no local previamente anunciados $\left(\S 1^{\circ}\right)$. O juiz fixará o prazo para que o perito e os assistentes entreguem as conclusões de seus trabalhos $\left(\S 2^{\circ}\right)$. Não há por que negar a possibilidade de as próprias partes, com fundamento no art. 191, ajustarem calendário para a prática desta perícia. Trata-se de mais um caso em que o novo CPC inova ao admitir, na prática dos atos processuais, ampla participação (e mais que isto, inegável protagonismo) das partes como verdadeiros condutores dos rumos do processo, aplicando, assim, a diretriz ampla do art. 190. Este protagonismo não impede, de qualquer sorte, o necessário (irrenunciável e inafastável) controle judicial sobre a regularidade da prática dos atos, a começar pela observância das exigências da hipótese de incidência do dispositivo: capacidade das partes e se tratar de causa que admita a auto composição (incisos I e II do caput). (BUENO, 2015. p. 316).
\end{abstract}

A atividade do perito ambiental no Brasil também é regida pela Lei de Crimes Ambientais - Lei Federal 9.605/98 -, pois expressamente preconiza o texto desta lei em seu artigo 19 que a perícia de constatação de dano ambiental, sempre que possível, fixará o montante do prejuízo causado para efeitos de prestação de fiança e cálculo de multa. Determinando também que a perícia produzida no inquérito civil ou no juízo cível poderá ser aproveitada no processo penal, instaurando-se o contraditório.

\title{
3 O CONCEITO DE DIREITO E O MEIO AMBIENTE ECOLOGICAMENTE EQUILIBRADO COMO ESPÉCIE DOS DIREITOS HUMANOS
}

O Direito foi, e é, pelo homem criado e recriado, portanto, a este primária e singularmente se destina. Ele, o Direito, costuma ser aceito como um conjunto de normas que 
rege a vida humana em sociedade. Noutras vezes também é reconhecido ou confundido como sinônimo de justiça ou de equidade.

Para o vocábulo Direito, temos, notavelmente, complexos conceitos reveladores da sua polissêmica e multifacetada sinonímia. Contudo, o entendimento prévio da amplitude do que é o Direito é indispensável, à compreensão da existência humana e da sua evolução histórica na sociedade que se perfaz, inicial e inevitavelmente, inserida nas facilidades e desafios característicos da dinamicidade, inconstância, e confluência de forças universais que, incontrolavelmente, se manifestam no meio ambiente, afetam e desafiam a capacidade de sobrevivência e continuidade da espécie humana em todo o planeta.

Uma acepção ou um conceito de Direito universalmente aceito, encontra muita dificuldade para ser equanimemente reconhecido, mesmo que até hoje, e depois que tantos estudiosos e pesquisadores tenham sobre este conceito se debruçado e lhe descrito científica ou empiricamente. Daí, a existência de tantas escolas interpretativas que o estudam e diferentemente o concebem, a exemplo da Escola Jusnaturalista; Escola Teológica; Escola Racionalista; Escola Histórica do Direito; Escola Marxista e Escola Sociológica do Direito, dentre outras.

$\mathrm{Na}$ atualidade, persistem antigas discussões e coexistem avançadas e abstrusas percepções e interpretações doutrinárias sobre a terminologia adequada para a classificação do direito humano, enquanto geração ou dimensão do Direito, especialmente, quando confrontadas com os limites, incongruências e imperfeições próprias e característica de um modelo produtivo, de cuja, natureza econômica e sistêmica, o capitalismo, dito moderno, não consegue se desassociar.

Ao se ponderar sobre estes temas que pautam as agendas das políticas econômicas, sociais e jurídicas, agora globalizadas e engrandecidas por conflitos de dimensões e espaços de repercussões mundiais, exige-se que previamente, se aprofundem as acepções e interpretações jurídicas, almejando melhor compreender os avanços das discussões doutrinárias que classificam os direitos humanos, especificamente aquelas que reconhecem o direito ao meio ambiente ecologicamente equilibrado, como uma de suas espécies.

O direito humano ao meio ambiente ecologicamente equilibrado já é reconhecimento em documentos e convenções internacionais e é considerado como um direito humano de "terceira geração", em virtude de sua natureza coletiva, de forma que seja diferenciado dos direitos humanos de "primeira geração", que são os direitos civis e políticos, de natureza individual e vinculados à liberdade, à igualdade, e à propriedade, e dos direitos humanos de "segunda geração", que são os direitos sociais, econômicos e culturais, associados ao trabalho, saúde, educação, 
etc. Mais recentemente, a teoria das "gerações de direitos" passou a ser criticada pela doutrina, por induzir ao equívoco de "um processo substitutivo, compartimentado e estanque", e a doutrina mais recente passou a substituir o termo "gerações" por "dimensões", uma vez que os direitos humanos resultam de "um processo de fazer-se e de complementariedade permanente. (SANTILLI, 2005, p. 59)

Neste ponto, convém lembrar que o homem vive e convive em sociedade. Para tanto, se utiliza de normas comportamentais preconcebidas como coercíveis, ou seja, são normas autorizadoras ou investidas politicamente da possibilidade do uso da força reconhecida em seus comandos legais, e, porque assim o são, também se configuram como integrantes de sistemas jurídicos complexos a que alguns chamam ou reconhecem como sinonímia do que é o Direito.

\subsection{As Forças do Meio Ambiente, do Capital e do Direito}

As forças dinâmicas e autônomas do meio ambiente, descortinam-se assim, passo a passo à humanidade, desvelando-se a cada um dos seus usos e reusos, através das adaptações e readaptações que lhe são implementadas.

Estas forças incontornáveis revelam algo de sistêmico e inerente à própria natureza, a qual os homens e mulheres insistem ou persistem em perscrutar, fazendo-se destas posturas e comportamentos perscrutadores, novos e instigantes desafios, imanentes a sua própria e ínsita busca do entendimento pela maior clareza da sua razão e motivo existencial, e, portanto, são condutas humanas influenciadas por percepções e crenças éticas, filosóficas, ideológicas, econômicas, legais e, deste modo, indubitavelmente consequentes e pertinentes ao que é o Direito.

Dessa compreensão prévia, advém, muitas implicações, dentre elas, podemos citar as que nos são lembrados por Miguel Tiago (2010), que nos adverte que a natureza é composta por um conjunto finito de recursos fundamentais à humanidade e ao seu desenvolvimento. Para ele, os dogmas ambientalistas se anexam ao conceito da própria natureza. Eles se anexam quando abordados e compreendidos enquanto entrelaçados ou sobrepostos com o sistema econômico capitalista que agudiza históricos problemas advindos da delapidação dos recursos que integram a natureza e sua inesgotável necessidade da geração de novos recursos financeiros, capital, que para tanto, apropria-se dos recursos naturais, mercantilizando-os, inclusive, predatoriamente.

Engels (1982) apud Miguel Tiago bem sintetizava este dilema ao afirmar que: 
O Capital tem de permanecer em crescimento e expansão, ou terá de morrer, permitindo assim a continuidade da sua força motriz: a taxa de lucro. Isso tem implicações muito concretas na gestão de recursos naturais e na sua apropriação, sendo que são, em grande medida, a fonte de toda a matéria-prima ou elementos fundamentais à vida de todos os seres humanos. Nesse caminho de crescimento e acumulação, os bens ambientais tornaram-se mercadorias à luz da perspectiva da classe dominante.

O imbróglio não se finaliza somente aí. O modo de produção capitalista transforma a natureza num objeto venal, comercializável, numa mera utilidade e assim o diz o autor João Valente Aguiar (2012).

O Capitalismo, não reconhece como deveria, à natureza, como um poder integrado em si mesmo. As descobertas feitas pelos homens sobre as leis explicáveis cientificamente, ou não, que regem a natureza de forma autônoma, surgem, como novas formas de submetê-la a ferocidade do capital, materializado por vezes, como objeto de consumo, e, por outras, como meio de produção.

Novamente, a acumulação monetária se retroalimenta sem se preocupar com as formas múltiplas de diversidades, nem com suas interconexões. Assim, adverte-nos Burkett (1999, p.161) apud Miguel Tiago "as vitórias humanas sobre a natureza, conquistadas pelo capitalismo, acabam por se tornar ilusórias" quando contrastadas com iminentes perigos face ao esquecimento de que os fatores e agentes não humanos também integram a natureza e podem, combinados ou não, enquanto forças autônomas, também lhes ser hostis, inclusive, ameaçando-lhes quanto às condições para a sobrevivência e reprodução das atuais e futuras gerações.

Por fim, cabe aqui previamente lembrar e reconhecer que tanto a natureza, o capitalismo, a sustentabilidade e o Direito são grandezas estruturais e conceitualmente complexas, importantes, coexistentes, dinâmicas e ainda corriqueiras e, por muitas vezes, irremediável e incompreensivelmente (super)sobrepostas.

\subsection{O Controverso Reconhecimento da Natureza como Sujeito de Direitos}

A discussão aqui pode ser travada, dentre outros tantos instigantes temas, na concepção do que é ou venha ser o Buen-Vivir, a exemplo do já ocorre na América Latina, ou na proporção ainda mais desafiadora dos que, hodiernamente, defendem que seja reconhecida à natureza, a condição de sujeito de direitos. 
Indaga, então, a repórter Verena Glass (2014) se "conceder a natureza a condição de sujeito de direitos pode ressignificar o conceito de 'desenvolvimento' e fortalecer um paradigma anticapitalista no que tange ao futuro do planeta".

Indago, agora, a semelhança do que fez anteriormente Verena Glass: O homem tem direitos universalmente reconhecidos, porque a natureza também não poderia então, tê-los, reconhecidos, defendidos e respeitados?

Não teria a natureza em todas as suas formas de vida, quer visíveis ou não, o direito de ser respeitada na condição de existir, coexistir, reinsurgir-se e reproduzir-se, e, assim cumprir seus desígnios na plenitude dos seus esforços vitais para a consecução dos seus ciclos biológicos?

Pode a humanidade conceber e retirar a natureza apenas da condição de mero objeto das relações jurídicas, reconhecendo-a, divisando-a também, como lhe sendo factível a condição de sujeito de direitos?

Há que se admitir, nesta visão conceptiva da natureza enquanto sujeito de Direitos, relevante serventia ou avanços jurídicos consideráveis para o futuro salutar da humanidade, ao se reconhecer legalmente a natureza como grandeza, não somente patrimonializável ou disponível, mas como uma dimensão ensejadora de maior reconhecimento, e como precipuamente dotada de um conjunto valorativo inestimável aos humanos, valores estes que não deveriam ser divisados pela ótica excludente do que lhes é economicamente apreciável.

Para as polêmicas questões acima relatadas, ainda não se têm respostas de todas conclusivas, até porque tanto a sociedade quanto a natureza se interconectam e se constituem por princípios que lhe são característicos e próprios.

Assim a sociedade e natureza interpenetram-se sem, todavia, se esvaziarem uma na
outra. Assim, importa perceber o duplo sentido entre ambos. Daí que se possam
enunciar princípios que balizam, em traços gerais, o circuito metabólico
sociedade/natureza, dentre eles: a) o princípio da dependência ecológica mostra que os
humanos estão dependentes da natureza para a sua sobrevivência (...) e que as
características da natureza com que se confrontam, causam um impacto significativo
no curso das suas vidas; b) o princípio do impacto ecológico demonstra que as ações
humanas, ações sociais têm importantes efeitos (planeados e não planeados) na
natureza. (HUGHES, 2000, p.88).

A constituição equatoriana serve de exemplo como diploma legal que alberga alguma destas concepções, entretanto, há que se buscar mais eficácia quanto a estes desígnios. Sabese que os valores e os direitos fundamentais à vida, à saúde, e a sadia qualidade de vida são 
juridicamente relevantes e inestimáveis ao bem estar humano. Assim também nos diz o preâmbulo do documento intitulado a Carta da Terra $(2000)^{2}$ :

\begin{abstract}
Estamos diante de um momento crítico na história da Terra, numa época em que a humanidade deve escolher o seu futuro. À medida que o mundo torna-se cada vez mais interdependente e frágil, o futuro reserva, ao mesmo tempo, grande perigo e grande esperança. Para seguir adiante, devemos reconhecer que, no meio de uma magnífica diversidade de culturas e formas de vida, somos uma família humana e uma comunidade terrestre com um destino comum. Devemos nos juntar para gerar uma sociedade sustentável global fundada no respeito pela natureza, nos direitos humanos universais, na justiça econômica e numa cultura da paz. Para chegar a este propósito, é imperativo que nós, os povos da Terra, declaremos nossa responsabilidade uns para com os outros, com a grande comunidade de vida e com as futuras gerações.
\end{abstract}

Para tanto, o mesmo documento assevera que a responsabilidade quanto ao futuro deve se dar de forma universal e afirma:

\begin{abstract}
Para realizar estas aspirações, devemos decidir viver com um sentido de responsabilidade universal, identificando-nos com a comunidade terrestre como um todo, bem como com nossas comunidades locais. Somos, ao mesmo tempo, cidadãos de nações diferentes e de um mundo no qual as dimensões local e global estão ligadas. Cada um compartilha responsabilidade pelo presente e pelo futuro bem-estar da família humana e de todo o mundo dos seres vivos. O espírito de solidariedade humana e de parentesco com toda a vida é fortalecido quando vivemos com reverência o mistério da existência, com gratidão pelo dom da vida e com humildade em relação ao lugar que o ser humano ocupa na natureza. Necessitamos com urgência de uma visão compartilhada de valores básicos para proporcionar um fundamento ético à comunidade mundial emergente.
\end{abstract}

Pelo exposto, depreende-se que a consciência de que a humanidade, assim como todos os demais detentores de vida integram a natureza, remete ao argumento de que talvez não fosse forçosamente necessário ao homem domá-la. Tal ideia pode ainda não ser hegemônica, mas parece agora despontar como um novo desafio ético ao entendimento dos que compõem o nosso tempo e comporá os tempos futuros. Este desígnio surge agora, inclusive, com a força de textos de lei constitucionalmente inseridos, portanto, em novos sistemas jurídicos que integram as mais diversas noções de sujeitos de direito.

\title{
4 O IMPERATIVO ÉTICO DA SUSTENTABILIDADE
}

As melhorias técnicas da sustentabilidade e do Direito quase sempre, se iniciam e

\footnotetext{
${ }^{2}$ Documento internacional de referência na defesa dos direitos sociais e do meio ambiente, ratificada em 2000 após amplo debate e discussão em todos os níveis, de escolas primárias a ministérios. Segundo o Ministério do Meio Ambiente, a construção do documento contou com a participação de 46 países e mais de 100 mil pessoas.
} 
prescindem de mudanças básicas de condutas, algumas delas enraizadas e historicamente comprometidas por processos econômicos, jurídicos e culturais fortes, sólidos e intensos. Neste sentido, são necessárias transformações de comportamentos individuais e coletivos, mas estas precisam de tempo para se materializar, porque é necessário mudar hábitos e crenças antigas, demandando mudanças pessoais complexas, mas não impossíveis de materializar.

Concomitantemente, os perigos e preocupações da sociedade global em vista dos reais valores da existência ecologicamente equilibrada somente denunciam que pelos critérios de eficiência, os esforços da humanidade são insatisfatórios para se evitar os problemas, danos e externalidades que crescentemente se avolumaram no meio ambiente ao longo da história até os dias atuais, causando impactos na biodiversidade e em toda comunidade de vida ainda existente no planeta.

As mudanças e técnicas de enfrentamento aos efeitos danosos são um imperativo ético e a forma mais adequada para se trabalhar este contexto cultural se dá pelos processos de educação ambiental ou ecológica, como nos afirmar Milaré ao dizer que:

\begin{abstract}
Ensinar esse saber ecológico, que também corresponde a sabedoria dos antigos, será o papel mais importante da educação no século 21. A alfabetização ecológica deve se tornar um requisito essencial para políticos, empresários e profissionais de todos os níveis - do ensino fundamental e médio até as universidades e os cursos de educação continuada e treinamento de profissionais. Vê-se que o aprofundamento do conceito de Ecologia nos conduz a uma revisão conceitual e - por que não dizer? -a uma revisão prática de hábitos sociais e até pessoais, voltada para uma vida saudável e sustentável. Esboça-se um novo estilo de civilização em consonância com as possibilidades da Terra. (MILARE, 2007, P. 7)
\end{abstract}

É forçoso reconhecer que a humanidade evoluiu no sentido do uso da tecnologia, da longevidade, da eficiência econômica, na produção quantitativa de bens, produtos e serviços, eliminando, inclusive, antigas pragas e doenças, produziu novos regramentos, regulamentações, institutos e diplomas jurídico-legais que sensibilizam, promovem e disciplinam os humanos quanto ao imperativo ético da sustentabilidade ao longo da sua existência, inclusive, respeitando-se o compromisso intergeracional das atuais e futuras gerações.

Entretanto, as diversas ciências há muito emitem documentos, relatórios técnicos, e prognósticos que alertam sobre os desafios inerentes ao futuro próximo da humanidade, diante dos inevitáveis malefícios e desastres socioambientais que já suportamos, acrescidos aos que teremos que suplantar, caso não sejam mais rapidamente implementadas medidas 
governamentais, condutas empresariais e atitudes socioindividuais, céleres e eficientes, que impositivamente promovam o direito humano ao meio ambiente ecologicamente equilibrado, com a correspondente obrigação do efetivo respeito aos limites da realidade ambiental, jurídica, econômica e social do planeta.

\section{CONCLUSÕES}

É identificável em todos os continentes que os acidentes ecológicos também podem ser considerados como resultantes negativas dos processos de globalização, que agora, na era da pós-modernidade, devem ser imprescindivelmente sopesados.

Nos últimos tempos muitas foram as teorias, métodos e inovações tecnológicas, inclusive na área da ciência jurídica, que buscam avançar na proteção e no regramento da questão ambiental. Incluso nestes esforços está a especificidade da perícia ambiental, que embora muito tenha evoluído, ainda tem muito a responder no que tange aos métodos para elucidação convincente das reais extensões e decorrências sucedidas como consequências nefastas dos danos ambientais.

A crescente concentração e adensamento populacional, o desequilíbrio ecológico e o crescimento econômico desordenado, ameaçam a qualidade de vida dos cidadãos planetários e tem deixado perplexas as estruturas políticas, científicas, governamentais e jurídicas, que muito antes deveriam ter previsto, implantado e adotado medidas e legislações que respeitassem a complexidade das forças dinâmicas da natureza, face as consequências danosas desse ruinoso estilo de vida contemporâneo, identificado como pós-moderno.

Olhando para o passado, parece ser pouco útil perscrutar se o culpado pelos diversos acidentes e danos ambientais foi a Economia, que falhou em não valorá-los, a Engenharia, que falhou em não prevê-los, ou o Direito que se omitiu ao não discipliná-los. Os danos ambientais e sua consequente responsabilização exigem conhecimentos multidisciplinares que envolvem diversos saberes científicos, resultantes das diversas ciências humanas, exatas e sociais.

Estes e tantos outros desafios ambientais não serão vencidos sem a promoção da educação ecológica e a confluência dos saberes, sem a humildade para que se reconheça as multifaces dos dilemas éticos que se nos afiguram na contemporaneidade: desenvolvermo-nos sim, cada um de nós e o mundo, de forma harmoniosa, equânime, parcimônica, social e ecologicamente equilibrada. 


\section{REFERÊNCIAS}

AGUIAR, João Valente. Uma reflexão teórica sobre as relações entre natureza e capitalismo. Disponível em: http://resistir.info/ecologia/ecologia_aguiar.html\#asterisco. Acesso em 12 set. 2016.

ALMEIDA, Josimar Ribeiro de. Perícia Ambiental Judicial e Securitária: Impacto, Dano e Passivo Ambiental. Rio de Janeiro: Editora Thex, 2011.

BARROS, Wellington Pacheco. Curso de Direito Ambiental. 5 ed. São Paulo: Atlas, 2008 .

BORGES, Marcos Afonso. Comentários ao Código de Processo Civil. São Paulo: Forense. 1974.

BUENO, Cassio Scarpinella. Novo Código de Processo Civil anotado. Bueno. São Paulo: Saraiva, 2015.

CABRAL, Alberto Franqueira. Manual da Prova Pericial. São Paulo: Qualitymark, 2010.

CUNHA, S. B. e GUERRA, A. J. T. Degradação Ambiental. Ed. Bertrand, Rio de Janeiro, 1996 apud Sandra Batista da. Avaliação e Perícia Ambiental. 9 ed. Rio de Janeiro: Bertrand Brasil, 2009.

ESPINDULA, Alberi. Perícia Criminal e Cível. 3 ed. São Paulo: Millennium, 2009.

FIORILLO, Celso Antônio Pacheco, 2006 apud DEON SETTE, Marli T. (org.) Direito Ambiental. MP Editora, 2010.

GLASS, Verena. Os Direitos da Natureza e a superação do desenvolvimentismo predatório. Disponível em: http://reporterbrasil.org.br/2014/06/os-direitos-da-natureza-e-asuperacao-do-desenvolvimentismo-predatorio/. Acesso em 11 set. 2016.

GRANZIERA, Maria Luiza Machado. Direito Ambiental. 2 ed. São Paulo: Atlas, 2011. 2010.

HUGHES, Jonathan. Ecology and Historical Materialism. Cambridg: University Press,

MIGUEL, Tiago. Contribuições para a reflexão - O capitalismo e a Natureza. Ed $\mathrm{n}^{\circ}$ 304 - Jan/Fev 2010. Disponível em: http://www.omilitante.pcp.pt/pt/304/Ambiente/378/Contribui\%C3\%A7\%C3\%B5es-para-areflex\%C3\%A3o---O-capitalismo-e-a-Natureza.htm. Acesso em 12 set. 2016.

MINISTÉRIO DO MEIO AMBIENTAL. Carta da Terra. Disponível em: www.mma.gov.br/estruturas/agenda21/_arquivos/carta_terra.doc $+\& c d=2 \& h l=p t-$ BR\&ct=clnk\&gl=br. Acesso 12 set. 2016. 
MIRALÉ, Édis. Direito Ambiental: doutrina, jurisprudência. 5 ed. São Paulo: Revista dos Tribunais, 2007.

NUNES, Rogério Reginato Alves. A perícia ambiental judicial e a perícia ambiental arbitral na resolução de conflitos ambientais. 1. ed. Rio de Janeiro: Sirius, 2014.

SANTILLI, Juliana. Socioambientalismo e novos direitos. São Paulo: Petrópolis, 2005.

TOCCHETO, Domingos. Perícia Ambiental Criminal. São Paulo: Millenium, 2010.

WAKIM, Vasconcelos Reis. Perícia Contábil e Ambiental. São Paulo: Atlas, 2012. 